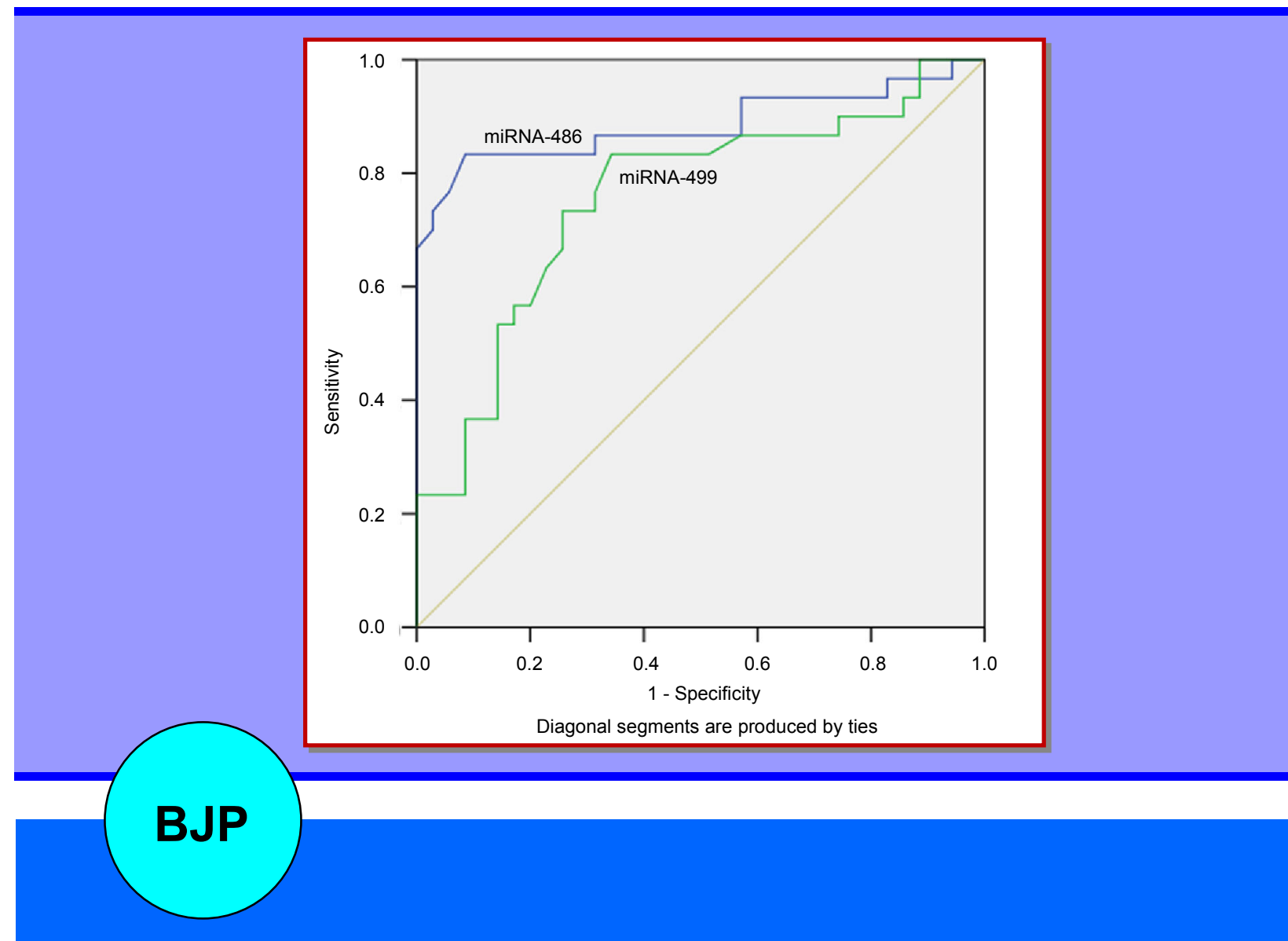

Bangladesh Journal of Pharmacology

Research Article

miRNA-486 and miRNA-499 in human plasma evaluate the clinical stages of lung cancer and play a role as a tumor suppressor in lung tumorigeneisis not pathogenesis 
Abstracted/indexed in Academic Search Complete, Asia Journals Online, Bangladesh Journals Online, Biological Abstracts, BIOSIS Previews, CAB Abstracts, Current Abstracts, Directory of Open Access Journals, EMBASE/Excerpta Medica, Google Scholar, HINARI (WHO), International Pharmaceutical Abstracts, Open J-gate, Science Citation Index Expanded, SCOPUS and Social Sciences Citation Index;

ISSN: $1991-0088$

\title{
miRNA-486 and miRNA-499 in human plasma evaluate the clinical stages of lung cancer and play a role as a tumor suppressor in lung tumorigeneisis not pathogenesis
}

\author{
Youchao Jia', Aimin Zang1, Yanguang Feng², Xiao-Fang Li', Ke Zhang3, Hefei Li3, Ruiyao \\ Wang3, Yaning Wei ${ }^{1}$ and Ran Huo ${ }^{1}$
}

${ }^{1}$ Hebei Key Laboratory of Cancer Radiotherapy and Chemotherapy, Department of Medical Oncology, Affiliated Hospital of Hebei University, Baoding, Hebei 071000, P. R. China; ${ }^{2}$ Department of Internal Medicine, People's Hospital of Qing Yuan District, Hebei, Baoding 071 100, P. R. China; ${ }^{3}$ Department of Thoracic surgery, Affiliated Hospital of Hebei University, Hebei, Baoding 071 000, P. R. China.

\begin{tabular}{|c|c|}
\hline \multicolumn{2}{|l|}{ Article Info } \\
\hline Received: & 12 October 20 \\
\hline & \\
\hline Available Online: & 29 jantuary 20 \\
\hline \multicolumn{2}{|c|}{ DOI: 10.3329/bjp.v11i1.25318 } \\
\hline \multicolumn{2}{|c|}{$\begin{array}{l}\text { Cite this article: } \\
\text { Jia Y, Zang A, Feng Y, Li X, Zhang K, } \\
\text { Li H, Wang R, Wei Y, Huo R. miRNA- } \\
486 \text { and miRNA-499 in human plasma } \\
\text { evaluate the clinical stages of lung } \\
\text { cancer and play a role as a tumor } \\
\text { suppressor in lung tumorigeneisis not } \\
\text { pathogenesis. Bangla desh J } \\
\text { Pharmacol. 2016; 11: 264-68. }\end{array}$} \\
\hline
\end{tabular}

\begin{abstract}
It was aimed to explore the expression level of miRNA-486 and miRNA-499 in the plasma of lung cancer patients and analysis their differences in expression. The expression level of both miRNA-486 and miRNA-499 in the plasma of non-small cell lung cancer (NSCLC) and small cell lung cancer (SCLC) were lower than that of the control group $(\mathrm{p}<0.05)$ and the decrease was more obvious in NSCLC. Compare with the miRNA-499, expression quantity in NSCLC patients plasma. There was statistical significance difference $(p<0.05)$ between III $\sim$ IV stage and I $\sim$ II stage. The expression quantity of miRNA in plasma of patients with extensive-stage SCLC was lower than that of patients with limited-stage SCLC $(\mathrm{p}<0.05)$. The sensitivity and specificity of plasms miRNA-486 respectively were $88.5 \%$ and $83.3 \%$. The expression of miRNA499 and miRNA-486 in lung cancer patients were up-regulated, and might be closely related to the occurrence and prognosis of lung cancer, and might be used as potential screening and prognosis index for lung cancer.
\end{abstract}

\section{Introduction}

miRNAs are tiny regulatory RNA that function to modulate the activity of specific mRNA and play important roles physiologic and pathologic processes, including tumorigenesis (Stefani and Slack, 2008). miRNAs are protected from endogenous RNase activity which is in a observably stable state in human plasma (Mitchell et al., 2008; Chen et al., 2008). miRNAs can be preserved stably from plasma in the ultra external environment (strong acids and alkalies, high temperature), that is the essential condition to serve as a useful biomarker for cancer diagnosis (Ho et al., 2010; Taylor and Gercel-Taylor, 2008; Huang et al., 2010). miR-486 is one of the most down-regulated micro RNAs in lung cancer (Wang et al., 2014). miR-486-5p may act as a tumor-suppressor, would provide potential diagnostic and therapeutic targets for the disease, contributing to the progression and metastasis of non-small cell lung cancer (NSCLC) by targeting ARHGAP5 (Wang et al., 2014).

miR-486 directly targets components of insulin growth factor (IGF) signaling including insulin-like growth factor 1 (IGF1), IGF1 receptor (IGF1R), and phosphoinositide-3-kinase, regulatory subunit 1 (alpha) (PIK3R1, or p85a) and functions as a potent tumor suppressor of lung cancer both in vitro and in vivo (Peng et al., 2013). miR-499 could contribute to poor prognosis by modulating cancer-related genes' expression and thus involve tumorigenesis and anti-chemotherapy (Qiu et al., 2015). It may influence the expression of a 
series cancer-related genes that might be annotated to immunity and defense, cell growth, tumor invasion and metastasis, cancer stem cell, and cell death, although no available evidences supported any genes to be known or predicted target genes of miR-499. We show here that miR-486 and miR-499 are down-regulated in patients' plasma with lung cancer. Plasma samples were obtained from newly diagnosed lung cancer patients and non-cancer controls. The expression level of both miRNA-486 and miRNA-499 in the plasma of NSCLC and small cell lung cance (SCLC) is lower than that of the control group $(\mathrm{p}<0.05)$, and the decrease is more obvious in NSCLC. Compared with expression of miRNA-499 with NSCLC, there is statistical significance difference $(p<0.05)$ between III $\sim$ IV stage and I $\sim$ II stage. Nevertheless, the expression of miRNA-486 in plasma of patients with extensive-stage SCLC is lower than that of patients with limited-stage SCLC $(p<0.05)$. The sensitivity and specificity of miR-486 is more precise than miR-499. Furthermore, the study provided novel evidence that the origination of lung cancer independent of miRNA-486 \& 499's function.

\section{Materials and Methods}

\section{Cohorts}

Plasma samples for lung cancer patients and controls were collected and archived between January 2014 and January 2015. There were 35 lung cancer (NSCLC 21, SCLC14) and 30 control cases (pneumonia and pulmonary tuberculosis). All samples were collected before any treatment, and miR-486 and miR-499 levels were analyzed respectively from these groups.

\section{Plasma extraction}

Plasma was extracted by centrifuging whole blood at $2,000 \mathrm{rpm}$ for $10 \mathrm{~min}$ at $4^{\circ} \mathrm{C}$ in 2 hours after whole blood was obtained from each patient and then frozen as separate aliquots at $-80^{\circ} \mathrm{C}$ for storage. $400 \mu \mathrm{L}$ of thawed plasma was boiled for $10 \mathrm{~min}$ at $100^{\circ} \mathrm{C}$ and then centrifuged at $13,000 \times \mathrm{xg}$ for $2 \mathrm{~min}$ at $4^{\circ} \mathrm{C}$.

\section{RNA isolation and cDNA synthesis}

miRNA was extracted directly from plasma by QIAzol Lysis Reagent and reverse-transcribed to complementary DNA. The RNA concentration was determined by measuring the absorbance at $260 \mathrm{~nm}$ using the NanoDrop ND1000 spectrophotometer and the purity of the RNA was estimated using the OD260/280 ratio. The RNA integrity was assessed by standard denaturing agarose gel electrophoresis, then the RNAs were used for labeling and array hybridi-zation. miR$486 \& 499$ and Caenorhabditis elegans miR-39 (cel-miR39) were then measured using quantitative reverse transcription polymerase chain reaction. the RNA was converted into cDNA using All-in-One ${ }^{\mathrm{TM}}$ miRNA qRT-
PCR Detection kit. Reaction system: Total RNA $2 \mathrm{uL}$, $2.5 \mathrm{U} / \mu \mathrm{L} 1$ Poly A Polymerase $1 \mu \mathrm{L}$, RTase Mix $1 \mu \mathrm{L}$, $5 X$ Reaction Buffer $5 \mu \mathrm{L}$, UTR-primer $(50 \mu \mathrm{M}) 1 \mu \mathrm{L}$, $\mathrm{ddH}_{2} \mathrm{O}$ (RNase/DNase free) to $25 \mu \mathrm{L}$. Hsa-miR-486: GATCAATCCTG TACTGAGCTGC. Hsa-miR-499: GGACGTCGTTA AGCTTGCAGTGA. cel-miR-39: GTACTCACCGGGT GTAAATCAG.

\section{Reverse transcription-PCR}

RT-PCR was performed by an Applied Biosystems 7500 real-time PCR system, with miR-486 \& 499 and cel-miR54 quantified using $2 \times$ All-in-One qPCR Mix. $25 \mu \mathrm{L}$ $\mathrm{dH}_{2} \mathrm{O}$ was mixed with $2 \times$ All-in-One qPCR Mix $10 \mu \mathrm{L}$, qPCR Forward Primer $(2 \mu \mathrm{M}) 2 \mu \mathrm{L}$, Universal PCR primer $(2 \mu \mathrm{M}) 1 \mu \mathrm{L}$, First strand cDNA $2 \mu \mathrm{L}$, ddH2O 5 $\mu \mathrm{L}$. RT-PCR was then performed at $95^{\circ} \mathrm{C}$ for $10 \mathrm{~min}$ at $95^{\circ} \mathrm{C}$ for $10 \mathrm{sec}$ at $60^{\circ} \mathrm{C}$ for $20 \mathrm{sec}$ and at $72^{\circ} \mathrm{C}$ for $10 \mathrm{sec}$ with the last three steps repeated for a total of 40 cycles. Each reaction was performed in triplicate.

\section{Statistical treatment}

A known quantity of synthetic cel-miR-39 was added for normalization after miR-486 \& 499 and cel-miR-54 were then measured using quantitative reverse transcription polymerase chain reaction. Data was analyzed using the $2^{-\triangle \Delta C T}$ method. Analyze expression of microRNAs with clinical cases data by non-parametric test for non-normal distribution. Wilcoxon test is performed on two groups comparing and KruskallWallis test is performed on multiunit groups.

\section{Results}

The expression level of both miRNA-486 and miRNA499 in the plasma of NSCLC and SCLC is lower than that of the control group $(p<0.05)$, and the decrease is more obviously NSCLC. There was a statistical significance on every comparing but the expression of miR499 in between SCLC with controls, or SCLC with NSCLC (Figure 1).

There was no statistical significance between the expression of miR-486 with gender, age, smoking, pathologic types, differentiation degree, extent of the primary tumor $(\mathrm{T})$ and regional lymph nodes $(\mathrm{N})$ $(\mathrm{p}>0.05)$, but distant metastases $(\mathrm{M})(\mathrm{p}=0.015)$ (Edge and Compton, 2010) in SCLC. The expression of miR499 don't have any statistical significance on clinicopathologic features in SCLC (Table I).

There was no statistical significance between the expression of miR-486 with clinicopathologic features in NSCLC. There was no statistical significance between the expression of miR-499 with gender, age, smoking, pathologic types, differentiation degree, extent of the primary tumor $(\mathrm{T})$ and regional lymph nodes $(\mathrm{N})$ $(p>0.05)$, but III/IV stage with I/II stage $(p=0.073)$ and 


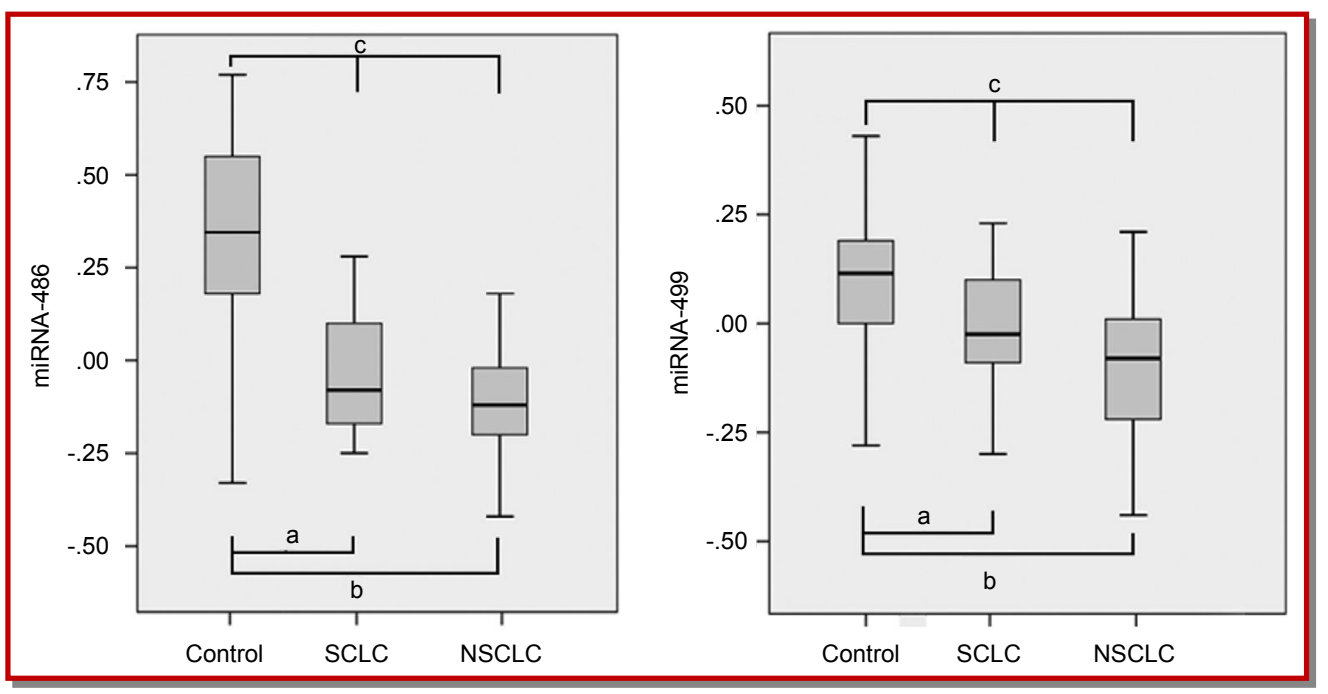

Figure 1: The expression of miR-486 and miR-499 of control group, SCLC and NSCLC. miRNA-486 was down-regulated in SCLC $\left({ }^{a} \mathrm{p}<0.01\right)$ and the decrease is more obviously NSCLC $\left({ }^{b} \mathrm{p}<0.01\right)$. There were significant differences among the three groups $\left({ }^{c} \mathrm{H}=\right.$ 28.712, $\mathrm{p}<0.001)$. The level of miR486 in SCLC rank above it in NSCLC ( $\mathrm{p}<0.05)$. miRNA-489 was down-regulated in SCLC $(\mathrm{a} p>0.05)$ and the decrease is more obviously NSCLC $\left({ }^{b} \mathrm{p}<0.05\right)$. There were significant differences among the three groups. $(\mathrm{cH}=$ 14.256, $\mathrm{p}=0.001)$. The level of miR486 in SCLC rank above it in NSCLC $(\mathrm{p}<0.05)$. There was not statistically significant between SCLC with NSCLC ( $>>0.05)$

Table I

\begin{tabular}{l} 
Relationship between the expression of the miRNA-486 and miRNA-499 in the plasma of SCLC with clinico- \\
pathologic features of lung cancer \\
\hline
\end{tabular}

low differentiation group with high differentiation group $(\mathrm{p}<0.05)$ (Table II).

There had more diagnostic value of miR-486 (0.790 0.979) than miR-499 $(0.635 \sim 0.878)$ by receiver operating characteristic curve $(\mathrm{p}<0.05)$ (Figure 2$)$.

\section{Discussion}

Several miRNAs were found to be altered more than 5fold between longer-survival and shorter-survival groups, and levels of miR-486 and miR-499 were significantly associated with overall survival. The microRNA signature also was consistently an independent predictor of overall survival ( $\mathrm{Hu}$ et al., 2010). The microRNA signature from the serum may serve as a non-invasive predictor for the overall survival of NSCLC.

miR-486 loss might be important in lung cancer development. miR-486 displayed lower expression levels in lung tumor tissues compared with the paired normal lung tissues (Shen et al., 2011). The findings in both surgical tissues and plasma specimens suggest that miR-486 down-regulation might play a role as a tumor suppressor in lung tumorigeneisis (Shen et al., 2011). We are pursuing a study to investigate possible mechanism of down-regulation of miR-486 in the develop- 
Table II

\begin{tabular}{|c|c|c|c|c|c|}
\hline \multirow{4}{*}{ Gender } & \multicolumn{3}{|c|}{ miRNA-486 } & \multicolumn{2}{|l|}{ miRNA-499 } \\
\hline & & $\mathrm{P}_{50}\left(\mathrm{P}_{25} \sim \mathrm{P}_{75}\right)^{\mathrm{a}}$ & $\mathrm{p}$ & $\mathrm{P}_{50}\left(\mathrm{P}_{25} \sim \mathrm{P}_{75}\right)$ & $\mathrm{p}$ \\
\hline & Man & $-0.13(-0.3 \sim 0.03)$ & 0999 & $-0.04(-0.1 \sim-0.02)$ & 0821 \\
\hline & Women & $-0.12(-0.2 \sim-0.04)$ & 0.999 & $-0.1(-0.16 \sim-0.01)$ & 0.831 \\
\hline \multirow[t]{2}{*}{ Age } & $\leq 60$ years & $-0.15(-0.30 \sim 0.10)$ & \multirow{2}{*}{0.972} & $-0.07(-0.31 \sim 0.07)$ & \multirow{2}{*}{0.803} \\
\hline & $>60$ years & $-0.11(-0.20 \sim-0.07)$ & & $-0.10(-0.16-0)$ & \\
\hline \multirow[t]{2}{*}{ Smoking } & No & $-0.15(-0.32 \sim-0.05)$ & \multirow{2}{*}{0.307} & $-0.08(-0.22 \sim-0.01)$ & \multirow{2}{*}{0.778} \\
\hline & Yes & $-0.1(-0.21 \sim-0.04))$ & & $-0.08(-0.25 \sim-0.01))$ & \\
\hline \multirow[t]{2}{*}{ pathologic types } & squamous carcinoma & $-0.1(-0.15 \sim 0.11)$ & \multirow{2}{*}{0.232} & $-0.05(-0.22 \sim 0.08)$ & \multirow{2}{*}{0.681} \\
\hline & adenocarcinoma & $-0.17(-0.26 \sim-0.04)$ & & $-0.09(-0.23 \sim 0.01)$ & \\
\hline \multirow[t]{2}{*}{ Lymph node metastasis } & No & $-0.02(-0.14 \sim 0.08)$ & \multirow{2}{*}{0.149} & $0.01(-0.04 \sim 0.08)$ & \multirow{2}{*}{0.121} \\
\hline & Yes & $-0.04(-0.03 \sim-0.06)$ & & $-0.07(-0.10 \sim-0.03)$ & \\
\hline \multirow[t]{2}{*}{ Tumor size } & $\leq 4 \mathrm{~cm}$ & $-0.1(-0.18 \sim 0.05)$ & \multirow{2}{*}{0.169} & $-0.06(-0.11 \sim 0.02)$ & \multirow{2}{*}{0.158} \\
\hline & $>4 \mathrm{~cm}$ & $-0.18(-0.32 \sim-0.04)$ & & $-0.09(-0.18 \sim-0.03)$ & \\
\hline \multirow[t]{2}{*}{ TNM } & I/II stage & $0.07(-0.11 \sim 0.13)$ & \multirow{2}{*}{0.059} & $0.05(-0.01 \sim 0.17)$ & \multirow{2}{*}{0.003} \\
\hline & III/IV stage & $-0.03(0.02 \sim-0.1)$ & & $-0.14(-0.26 \sim-0.05)$ & \\
\hline
\end{tabular}

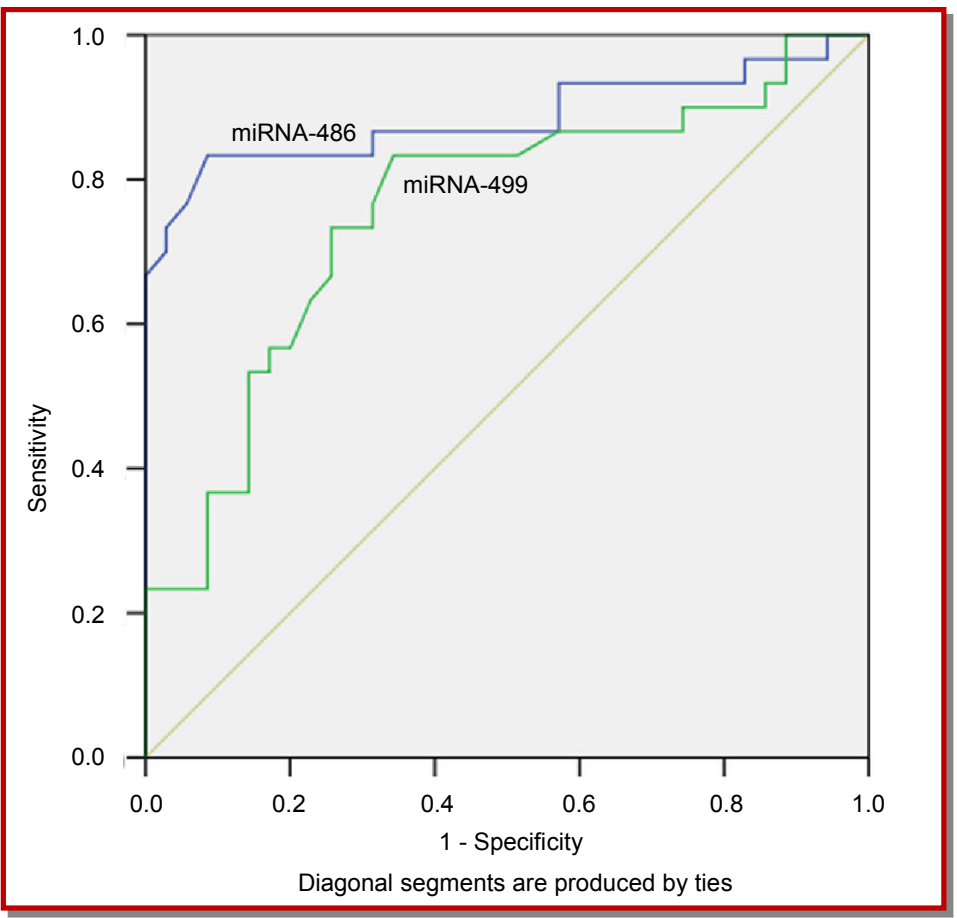

Figure 2: The evaluation of miR-486 and miR-499 on diagnosis of lung cancer by receiver operating characteristic curve. ROC curve of miR-486 and miR-499 for the diagnosis of lung cancer. The area under the ROC curve was 0.885 and 0.757 respectively $(\mathrm{p}<0.05)$. Diagonal segments are produced by ties

ment and progress of lung cancer. In our study, the expression level of both miRNA-486 in the plasma of NSCLC and SCLC is lower than that of the control group, and the decrease is more obviously NSCLC (Figure 1). As the one part of microRNA groups, miR486 remains maintain expressing on finite concentration, it down-regulated as the suppressor with tumor formation. So, it could not down-regulated enough in SCLC which is more invasive than NSCLC. It just explained the result in above paragraphs that no statistical significance between the expression of miR486 with clinicopathologic features which associated with pathogenesis and risk in NSCLC and SCLC but extensive-stage SCLC is lower than that of patients with limited-stage SCLC. At the same time, miR-486 can be a predictive biomarker for prognosis of lung cancer to 
monitor the neoplasm recurrence.

miR-499 levels are higher in patients with stable chronic obstructive pulmonary diseases (COPD) compared with controls (Donaldson et al., 2013) and there was none association between miR-499 with risk of NSCLC (Vinci et al., 2011). We got the similar data that the expression of miR-499 don't have any statistical significance on clinicopathologic features in SCLC and NSCLC, but I/II stage with III/IV stage and differentiation degree in NSCLC. miR-499 could contribute to poor prognosis by modulating cancer-related genes' expression and thus involve tumorigenesis and anti-chemotherapy, which maybe a useful biomarker to predict lung cancer patients' prognosis (Qiu et al., 2015).

\section{Conclusion}

miR-486 and miR-499, as a tumor suppressor in lung tumorigeneisis, might be evaluate the clinical stages of lung cancer and predict lung cancer patients' prognosis. But, they were not directly associated with risk and pathogenesis for lung cancer.

\section{Acknowledgement}

This study was supported by Sci-Tech Support Plan from Baoding Science And Technology Board (15ZF042)

\section{Conflict of Interest}

None.

\section{References}

Chen X, Ba Y, Ma L, Cai X, Yin Y, Wang K, Guo J, Zhang Y, Chen J, Guo X, Li Q, Li X, Wang W, Zhang Y, Wang J, Jiang $X$, Xiang $Y, X u C$, Zheng $P$, Zhang J, Li R,Zhang $\mathrm{H}$, Shang $X$, Gong $T$, Ning $G$, Wang J, Zen $K$, Zhang J, Zhang CY. Characterization of microRNAs in serum: A novel class of biomarkers for diagnosis of cancer and other diseases. Cell Res. 2008; 18: 997-1006.

Donaldson A, Natanek SA, Lewis A, Man WD, Hopkinson NS, Polkey MI, Kemp PR. Increased skeletal muscle-specific microRNA in the blood of patients with COPD. Thorax 2013; 68: 1140-49.

Edge SB, Compton CC. The American Joint Committee on Cancer: The 7th edition of the AJCC cancer staging manual and the future of TNM. Ann Surg Oncol. 2010; 17: 1471-74.

Ho AS, Huang X, Cao H, Christman-Skieller C, Bennewith K, Le QT, Koong AC. Circulating miR-210 as a novel hypoxia marker in pancreatic cancer. Translational Oncol. 2010; 3: 109-13.

Huang Z, Huang D, Ni S, Peng Z, Sheng W, Du X. Plasma
microRNAs are promising novel biomarkers for early detection of colorectal cancer. Int J Cancer. 2010; 127: 118-26.

Hu Z, Chen X, Zhao Y, Tian T, Jin G, Shu Y, Chen Y, Xu L, Zen $\mathrm{K}$, Zhang $\mathrm{C}$, Shen $\mathrm{H}$. Serum MicroRNA signatures identified in a genome-wide serum MicroRNA expression profiling predict survival of non-small-cell lung cancer. J Clin Oncol. 2010; 28: 1721-26.

Mitchell PS, Parkin RK, Kroh EM, Fritz BR, Wyman SK, Pogosova-Agadjanyan EL, Peterson A, Noteboom J, O'Briant KC, Allen A, Lin DW, Urban N, Drescher CW, Knudsen BS, Stirewalt DL, Gentleman R, Vessella RL, Nelson PS, Martin DB, Tewari M. Circulating microRNAs as stable blood-based markers for cancer detection. Proc Natl Acad Sci USA. 2008; 105: 10513-18.

Peng Y, Dai Y, Hitchcock C, Yang X, Kassis ES, Liu L, Luo Z, Sun HL, Cui R, Wei H, Kim T, Lee TJ, Jeon YJ, Nuovo GJ, Volinia S, He Q, Yu J, Nana-Sinkam P, Croce CM. Insulin growth factor signaling is regulated by microRNA-486, an under-expressed microRNA in lung cancer. Proc Natl Acad Sci. 2013; 110: 15043-48.

Qiu F, Yang L, Ling X, Yang R, Yang X, Zhang L, Fang W, Xie C, Huang D, Zhou Y, Lu J. Sequence variation in mature microRNA-499 confers unfavorable prognosis of lung cancer patients treated with platinum-based chemotherapy. Clin Cancer Res. 2015; 21: 1602-13.

Stefani G, Slack FJ. Small non-coding RNAs in animal development. Nat Rev Mol Cell Biol. 2008; 9: 219-30.

Shen J, Todd N W, Zhang $\mathrm{H}, \mathrm{Yu}$ L, Lingxiao $X$, Mei Y, Guarnera M, Liao J, Chou A, Lu CL, Jiang Z, Fang H, Katz RL, Jiang F. Plasma microRNAs as potential biomarkers for non-small-cell lung cancer. Lab Invest. 2011; 91: 579-87.

Shen J, Liu Z, Todd NW, Zhang H, Liao J, Yu L, Guarnera MA, Li R, Cai L, Zhan M, Jiang F. Diagnosis of lung cancer in individuals with solitary pulmonary nodules by plasma microRNA biomarkers. BMC Cancer. 2011; 11: 374.

Taylor DD, Gercel-Taylor C. MicroRNA signatures of tumorderived exosomes as diagnostic biomarkers of ovarian cancer. Gynecol Oncol. 2008; 110: 13-21.

Vinci S, Gelmini S, Pratesi N, Conti S, Malentacchi F, Simi L, Pazzagli M, Orlando C. Genetic variants in miR-146a, miR -149, miR-196a2, miR-499 and their influence on relative expression in lung cancers. Clin Chem Lab Med. 2011; 49: 2073-80.

Wang J, Tian X, Han R, Zhang X, Wang X, Shen H1, Xue L, Liu Y, Yan X, Shen J, Mannoor K, Deepak J, Donahue JM, Stass SA, Xing L, Jiang F. Down-regulation of miR-486-5p contributes to tumor progression and metastasis by targeting protumorigenic ARHGAP5 in lung cancer. Oncogene 2014; 33: 1181-89.

\begin{tabular}{l|} 
Author Info \\
Xiao-Fang Li (Principal contact) \\
e-mail: xiaofang_li33@sina.com \\
First two authors contributed equally
\end{tabular}




\section{Your feedback about this paper}

1. Number of times you have read this paper 0

2. Quality of paper Click

3. Your comments 